\title{
An Analytical Study on the Performance of Pre- Stressed Box Girder Bridges
}

\author{
Obaid Yousouf ${ }^{1}$, Lovekesh Gaur ${ }^{2}$ \\ ${ }^{1}$ M.Tech Student, Department of Civil Engineering, Shree Siddhivinayak Group of Institutions, Bilaspur, Affiliated to Kurukshetra University, \\ Kurukshetra, Haryana, India \\ ${ }^{2}$ Assistant Professor, Department of Civil Engineering, Shree Siddhivinayak Group of Institutions, Bilaspur, Affiliated to Kurukshetra \\ University, Kurukshetra, Haryana, India
}

\begin{abstract}
In conventional reinforced concrete T-Beam Bridges spanning more than 15m, large concrete sections are required to resist imposed vehicular loads. These large sections create heavy dead weight (self weight), requiring therefore large reinforcement ratio to encounter tensile stresses and simultaneously produce excessive deflection. To reduce dead weight and control the deflection, prestressed concrete sections are found efficient from the view of economy and structural behavior. Since in curved, skew and eccentrically loaded bridge decks, torsional stresses are produced to the large extent leading to by and large unwanted shear deformations. Box girders because of having high torsional rigidity can be effective in resisting torsional stresses. Therefore, prestressed box girder bridge decks with low dead weight can be used in the construction of reasonably long span bridges (15m-40m) with better structural performance. It is therefore imperative to carry parametric study on prestressed box girder bridges with due consideration to performance, economy and structural efficiency. In this study, a two lane prestressed box girder bridge has been analyzed under class AA loading and the ideal sections have been proposed with strict deflection control in an economical way.
\end{abstract}

Keywords: Class AA Loading, Deflection, Pre- stressed Box Girder Bridges, T - Beam Bridges, Torsional Rigidity

\section{Introduction}

Box girders have gained popularity in bridge engineering fraternity because of its better stability, serviceability, economy, aesthetic appearance and structural efficiency. Reinforced concrete box girders are used generally in highway structures with maximum economical span of about $35 \mathrm{~m}$. Beyond this span, there is substantial increase in size resulting in higher dead loads. For such long spans, post tensioned box girder bridges may be used where the dead load is balanced by prestressing force so that the sectional dimensions are required to balance live loads only. Post tensioned tendons are used in the longitudinal direction, where their use can produce more slender girders and longer spans.

A box girder is a bridge in which the main beams comprise girders in the shape of a hollow box. The box is typically rectangular or trapezoidal in cross-section. The closed cell has a much greater torsional stiffness and strength than an open section and it is this feature which is the usual reason for choosing a box girder configuration. Box girder bridges are commonly used for highway flyovers and for modern elevated structures of light rail transport. Although normally the box girder bridge is a form of Beam Bridge, box girders may also be used on cable-stayed bridges and other forms. Box girders are rarely used in buildings, while they may be used in special circumstances, such as when loads are carried eccentrically to the beam axis. The interior of the box can be used for services and in large spans can be used for traffic.

\section{Literature Review}

Zdenek P. Bazant et al. [1] In their paper presented that the main cause of the gross underestimation of the observed 18year deflections of the Koror-Babeldoab (KB) bridge in Palau was the use of an obsolete standard recommendation for creep. Motivated by this finding, a search for data on similar bridges was undertaken. The results amount to a wakeup call: 56 other large span, prestressed concrete, segmentally erected box girders ( 66 by time of proof) have already been found to exhibit excessive long-time deflections and it is likely that more such girders exist.

Amin Ghali, and Ramez B. Gayed [2] In their paper showed that modern design requires satisfactory serviceability sustainable for a long life span. The camber or the deflection must not be excessive during the design lifespan. The paper concerns the state of the art technology on prediction of the most probable long term deflection. The improvements and the wide variation of concrete and reinforcement properties cannot be accounted for in modern design by the use of empirical or code multipliers to relate the long term to immediate deflections. The use of appropriate time dependent parameters for the concrete and the reinforcement, combined with analysis based on equilibrium and compatibility principles, is necessary for the design of modern structures to sustain satisfactory serviceability for longer lifespan. The present paper puts forward the most reliable technique of long term deflection prediction, using the current knowledge of the time dependent material properties. The presented analysis can be used in the calibration of computer programs adopted in practice.

Volume 6 Issue 7, July 2017 


\section{International Journal of Science and Research (IJSR) \\ ISSN (Online): 2319-7064 \\ Index Copernicus Value (2015): 78.96 | Impact Factor (2015): 6.391}

The two computer programs TDA and CGS were used to calculate the immediate and the long term strain and stress distributions in a reinforced concrete section with or without prestressing. TDA can be used only for sections having an axis of symmetry, (y). The geometry of a general section is entered for CGS as $(\mathrm{x}, \mathrm{y})$ coordinates of nodes on the perimeter; the computer calculates the area properties from the coordinates using equations given in Kawakami and Ghali (1996). The computer program RPM (Elbadry and Ghali 2006) calculates deflection of a member from curvatures at a number of sections.

Phani Kumar. Ch et al. [3] "Analysis and Design of Pretressed Box Girder Bridge by IRRC 112: 2011". This paper shows that the various span to depth ratio area taken for the analysis of box girder bridges, and for all the cases, deflection and stresses are within the permissible limits.

As the depth of the box girder decreases, the prestressing force decreases and number of cables decreases. Because of prestressing, more strength of concrete is utilized and also well governs serviceability.

However, least focus has been given on the parametric study and control of deflection of box girder bridges. Therefore, it is imperative to carry out parametric investigation on box girder bridges to arrive for economically safe prestressed box girder sections having controlled deflection, low dead weight and better structural performance with adequate torsional rigidity.

\section{Methodology}

In this study a two lane simply supported trapezoidal box Girder Bridge is taken for analysis. It is assumed that the dead weight of the box girder bridge is taken by prestressing only. Also the deflections due to dead weight are likely to take place in the construction phase and are therefore not taken up for the study. The bridge section is analyzed for IRC class AA loading only and for various span/depth (L/d) and thickness/depth ( $t / d)$ ratios to arrive for the bridge sections satisfying both, stress criteria as well as deflection criteria. The thickness of the top slab, bottom slab and the inclined webs is taken same for ease out of the calculations. A typical trapezoidal box girder bridge section taken for the analysis is shown in the fig below. The parameters of the section considered are as under:

$\mathrm{b}=$ top or deck slab width of the box girder bridge

$\mathrm{a}=$ bottom or soffit slab width of the box girder bridge

$\mathrm{d}=$ overall depth of the box girder bridge

$\mathrm{t}=$ thickness of deck slab, inclined web slabs as well as of soffit slab of the section

$\varnothing=$ the angle at which the inclined web slabs are inclined to the soffit slab

$I_{1}=$ Moment of inertia of the top slab of the box girder bridge section

$I_{2}=$ Moment of inertia of the inclined web slabs of the box girder bridge section
$\mathrm{I}_{3}=$ Moment of inertia of the bottom or soffit slab of the box girder bridge section.

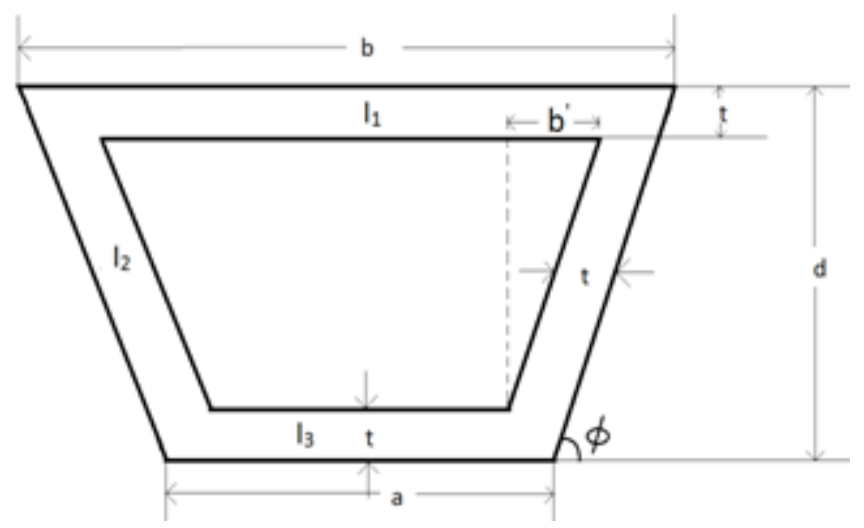

Figure 1; A typical box girder section taken for the study

The moment of inertia of the section is approximately given by,

$$
\mathbf{I}=\mathbf{I}_{1}+\mathbf{I}_{2}+\mathbf{I}_{3}
$$

Now, moment of inertia of the section for $\emptyset=45^{\circ}$ and for a two lane bridge of carriageway width $7.5 \mathrm{~m}$ is calculated as:

$$
\begin{gathered}
\boldsymbol{I}=(5000-0.667 d) t^{3}+0.667 t d^{3}+7500(d-t) d t+ \\
{\left[2 d t^{2}-(15000+2 d) d t\right]\left[\frac{22500-2 d}{7500-d} \times \frac{d}{6}\right]+} \\
(15000 t)\left(\frac{22500-2 d}{7500-d} \times \frac{d}{6}\right)^{2}
\end{gathered}
$$

Calculations for the maximum deflection of the bridge under class AA loading:

(a) Case I: Class AA Tracked vehicle

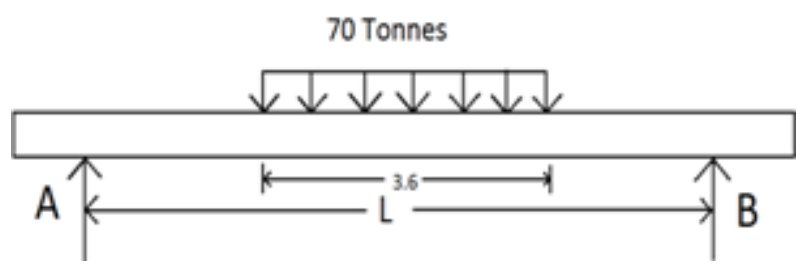

Figure 2; Placement of tracked vehicle loading on the bridge for maximum deflection

The maximum deflection of the bridge is obtained when the load acts at its centre. Hence assuming the load of the vehicle (70 tonnes for tracked vehicle) acting at the centre of the bridge. Therefore, maximum deflection is given by,

$$
\delta_{\max }=\frac{W L^{3}}{48 E I}
$$

Adopting $\mathrm{M}_{45}$ grade of concrete; $\mathrm{E}=5000 \sqrt{45} \mathrm{MPa}$

Maximum deflection of the bridge with impact of loading for class AA tracked vehicle is calculated as

$$
\delta_{\max }=\frac{0.478 L^{3}}{I}
$$




\section{International Journal of Science and Research (IJSR) \\ ISSN (Online): 2319-7064 \\ Index Copernicus Value (2015): 78.96 | Impact Factor (2015): 6.391}

The above equation is solved for different $\mathrm{L} / \mathrm{d} \& \mathrm{t} / \mathrm{d}$ ratios $\{\mathrm{L} / \mathrm{d}=10,11,12,13 \ldots 50 \& \mathrm{t} / \mathrm{d}=0.05,0.10,0.15,0.20$ and $0.25\}$ and the graphical relation between different ratios (L/d $\& \mathrm{t} / \mathrm{d}$ ) and maximum deflection is obtained.

(b) Case II: Class AA Wheeled vehicle

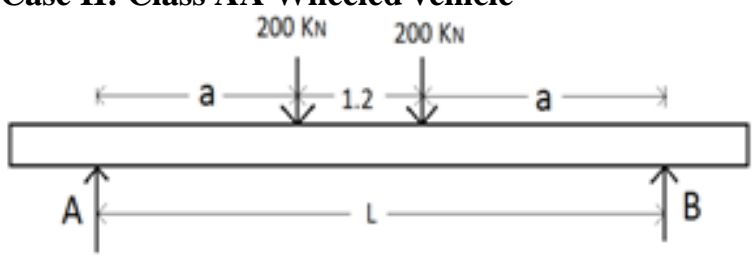

Figure 3; Placement of wheeled vehicle loading on the bridge for maximum deflection

The maximum deflection for above case is given by,

$$
\delta_{\text {max }}=W\left[\frac{L-1.2}{2}\right]\left[\frac{3 L^{2}-4\left(\frac{L-1.2}{2}\right)^{2}}{24 E I}\right]
$$

The impact of loading due to the wheeled vehicle on bridges spanning more than $12 \mathrm{~m}$ changes continuously with the span of the bridge (as per IRC: 6 2000). Normally, prestressed box girder bridges are designed for spans of $40 \mathrm{~m}$ to $60 \mathrm{~m}$. Therefore, for the generalization of results and for ease out of the calculations, the impact due to the wheeled vehicle on the box girder bridge is considered as $10 \%$.

Therefore, maximum deflection of the bridge with impact of loading for class AA wheeled loading is calculated as;

$$
\delta_{\max }=0.136\left[\frac{(L-1.2) 3 L^{2}-(L-1.2)^{3}}{I}\right]
$$

The above equation is solved for different $L / d \& t / d$ ratios and the graphical relation between the different ratios $(\mathrm{L} / \mathrm{d} \& \mathrm{t} / \mathrm{d})$ and maximum deflection is obtained.

\section{Results}

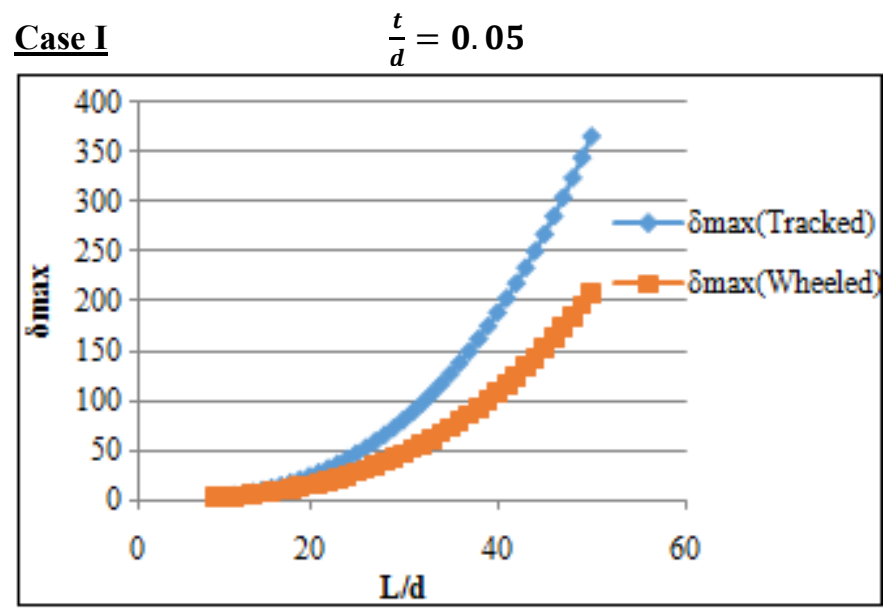

Figure 4; Deflection profile of bridge under class AA loading of $\operatorname{span}(\mathrm{L})=20 \mathrm{~m}$

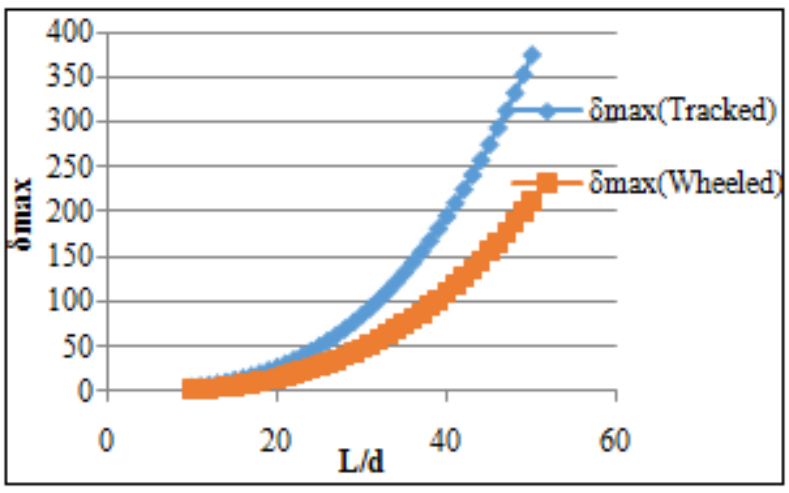

Figure 5: Deflection profile of bridge under class AA loading of $\operatorname{span}(\mathrm{L})=30 \mathrm{~m}$

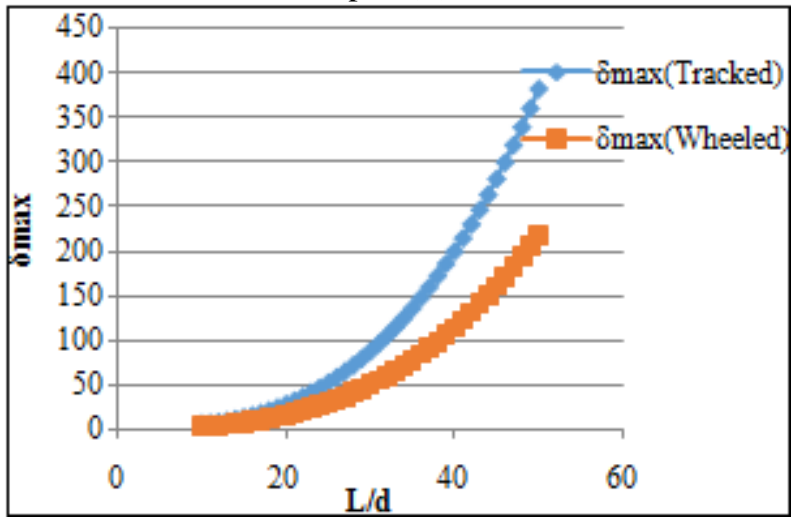

Figure 6; Deflection profile of bridge under class AA loading of $\operatorname{span}(\mathrm{L})=40 \mathrm{~m}$

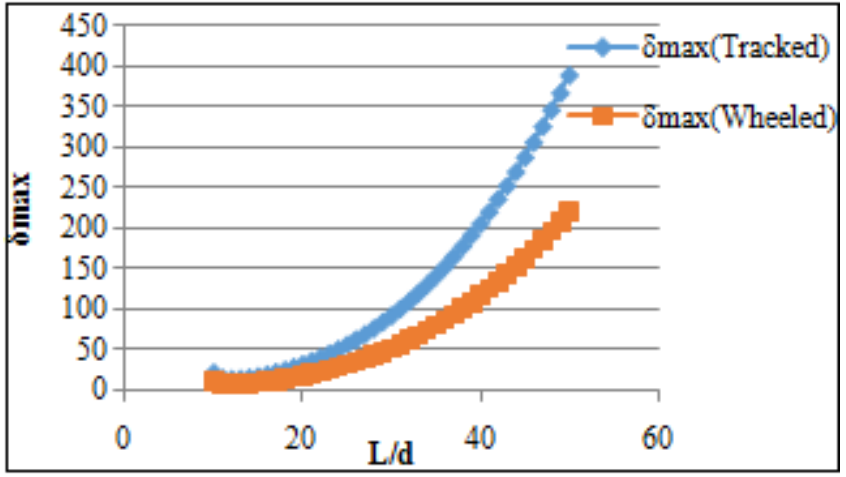

Figure 7; Deflection profile of bridge under class AA loading of $\operatorname{span}(\mathrm{L})=50 \mathrm{~m}$

Case II $\quad \frac{L}{d}=10$

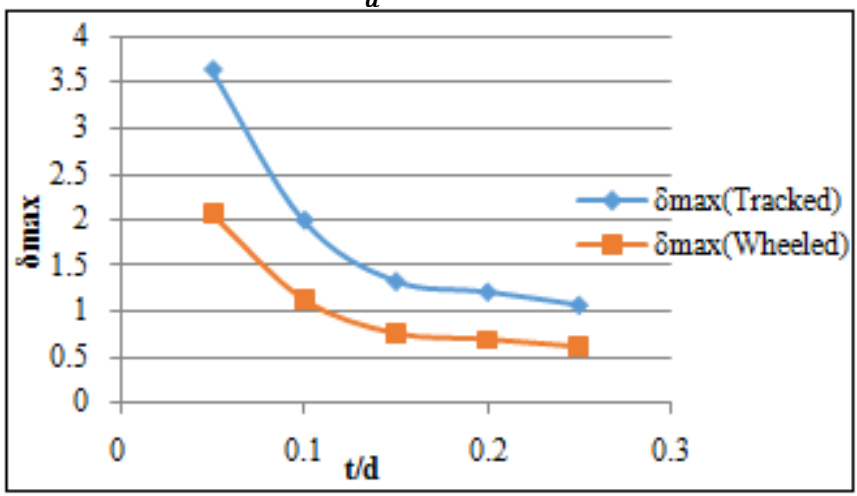

Figure 8: Deflection profile of bridge under class AA loading of $\operatorname{span}(\mathrm{L})=20 \mathrm{~m}$

Volume 6 Issue 7, July 2017 


\section{International Journal of Science and Research (IJSR)}

ISSN (Online): 2319-7064

Index Copernicus Value (2015): 78.96 | Impact Factor (2015): 6.391

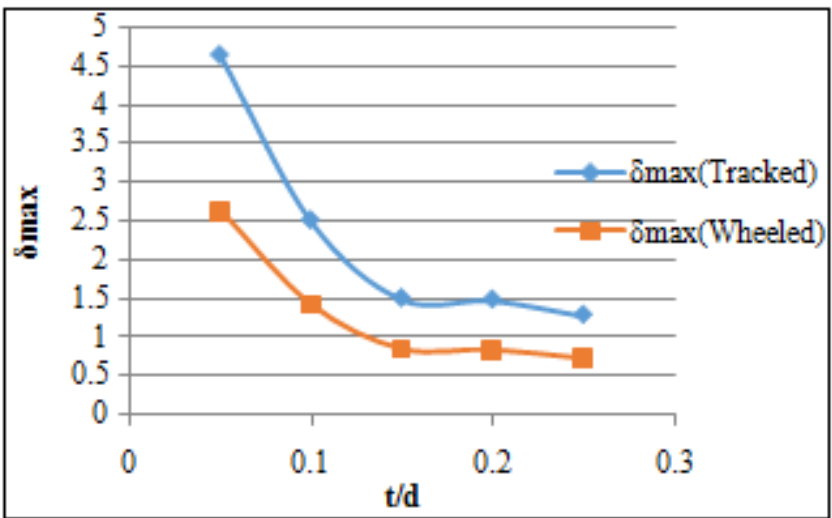

Figure 9: Deflection profile of bridge under class AA loading of $\operatorname{span}(\mathrm{L})=30 \mathrm{~m}$

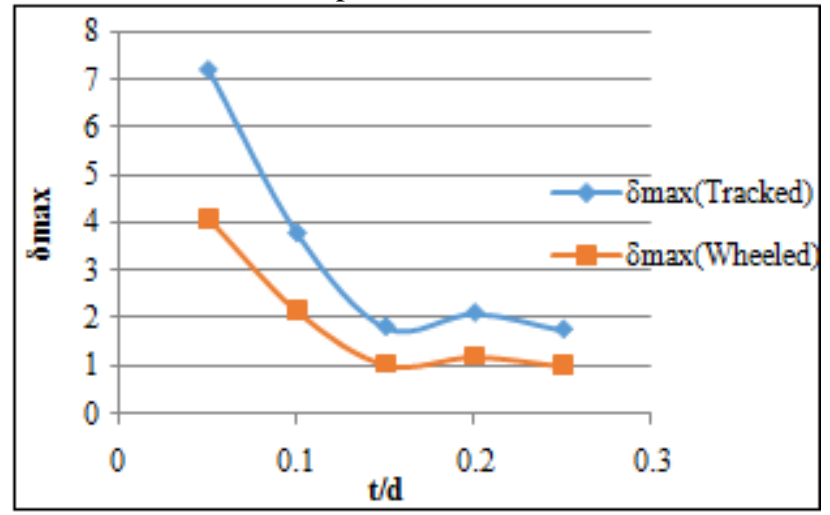

Figure 10: Deflection profile of bridge under class AA loading of $\operatorname{span}(\mathrm{L})=40 \mathrm{~m}$

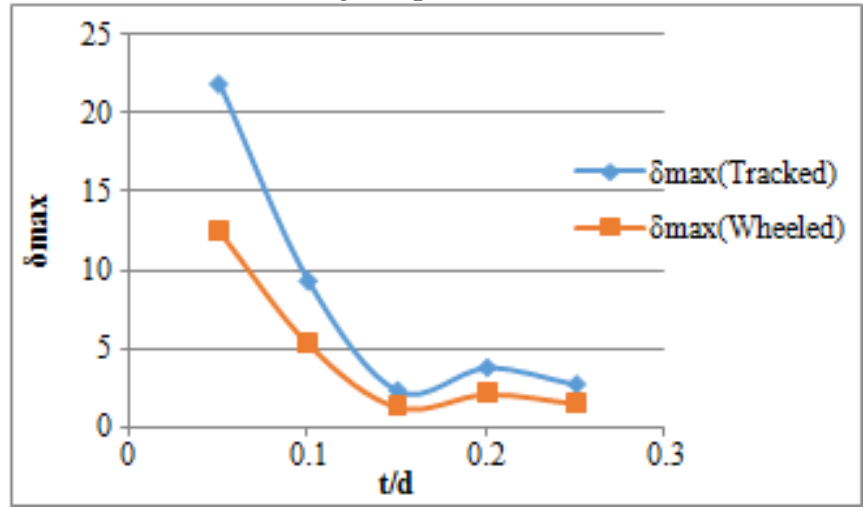

Figure 11: Deflection profile of bridge under class AA loading of $\operatorname{span}(\mathrm{L})=50 \mathrm{~m}$

\section{Conclusions}

The requirement of the fulfillment of deflection criteria of prestressed box girder bridges is most essential for the serviceability and safety of these bridges. Normally, the deflection should not be more than L/800. This value is quiet lesser than those of buildings i.e. L/350. This is because undesirable deflection in box girder bridges produces unwanted minor cracks. These cracks result in tremendous relaxation of prestresses in the tendons and hence the failure of the bridge. Therefore, in addition to strength, due consideration should be given to the control of deflection.
In this study, two lane prestressed box girder bridge have been analyzed under class AA loading and the ideal sections have been proposed with strict deflection control in an economical way. The following conclusions have been drawn from the study:

1) For a given value of $t / d$, the deflection produced by class AA Tracked vehicle is more than the wheeled vehicle. This shows that if the worst effect in a prestressed box girder bridge is created by wheeled vehicle (Maximum BM \& $\mathrm{SF}$ ), still the bridge should be checked for maximum deflection due to tracked vehicle.

2) For a given value of $t / d$ and $L / d$ value beyond 30 - 40 takes sharp increase in deflection both by wheeled and tracked vehicle. Therefore, it would be safer to adopt $\mathrm{L} / \mathrm{d}$ value lesser than 40 for prestressed box girder bridges from the view of deflection criteria.

3) For a given value of $L / d$, the increase in $t / d$ ratio decreases the deflection in general and it is seen that with $t / d$ value greater than or equal to 0.15 , the deflection is quiet lesser than the value with $t / d$ lesser than 0.15 . Therefore, for the control of deflection, $\mathrm{t} / \mathrm{d}$ value around 0.15 to 0.2 is fair enough.

4) At low $\mathrm{L} / \mathrm{d} \operatorname{ratio}(\mathrm{L} / \mathrm{d}=10$, in this study ), the deflection attains optimum value at $\mathrm{t} / \mathrm{d}=0.25$, therefore, extra safety from deflection point of view.

\section{Future Scope}

The work has been done for prestressed box girder bridges and can be extended for T- Beam and Truss Girder Bridges.

\section{References}

[1] Bazant, Z. P. , Yu, Q. , Huber, M. H. , Kristek, V. , and Bitmar, Z. "Wakeup call for creep, myth about size effect and black holes in safety. What to improve in fib Model Code Draft," Proc., fib Symp., FédérationInternationale du Béton (fib), Lausanne, Switzerland, . (2011)

[2] Amin Ghali and Ramez B. Gayed "Sustainable Serviceability of Structural Concrete: Control of Deflection and Cracking" Journal od Structural Engineering, Vol 140 Issue 7 - July 2014

[3] Phani Kumar. Ch, S.V.V.K. Babu and D. Aditya Sai Ram "Analysis and Design of Prestressed Box Girder Bridges by IRC 112- 2011" International Journal of Constructive Research in Civil Engineering IJCRCE Vol 2, Issue 2, 2016, PP-10. ISSN 2454-8693(online).

[4] Zdeněk P. Bažant, Hon.M.ASCE; Qiang Yu; and GuangHua Li, Excessive Long-Time Deflections of Prestressed Box Girders. I: Record-Span Bridge in Palau and Other Paradigms, JOURNAL OF STRUCTURAL ENGINEERING (C) ASCE / JUNE 2012

[5] IRC 6: 2000, "Standard specifications and code of practice for road bridges"

[6] Text book "Prestressed Concrete" by N KRISHNA RAJU, Fifth Edition, Tata McGraw Hills. 